\title{
O paradoxo do afeto no (des)ensino de literatura
}

\section{Odete Firmino Alhadas Salgado}

Pontifícia Universidade Católica do Rio de Janeiro - PUC-Rio/CNPq

\begin{abstract}
Resumo
O objetivo deste artigo é discutir o ensino de literatura, que muitas vezes trata a materialidade do texto de forma superficial, e o afeto que a leitura proporciona a partir de uma perspectiva sociossemiótica de linguagem. Dessa forma, entendendo que a literatura é uma linguagem, procuro trabalhar a ideia de que textos literários também estão acessíveis para análises linguísticas, pois o texto é a própria linguagem em uso (HALLIDAY, 2002 [1964]; 1994). Os significados construídos pelo autor em seu discurso literário estão intimamente ligados ao contexto de produção e circulação da obra, ou seja, o texto só acontece em seu ambiente social. Em relação ao afeto, centro das emoções que expressamos e o centro dos sentimentos institucionalizados (MARTIN e WHITE, 2005), é preciso compreender que o prazer da leitura deve figurar como protagonista no processo de ensino-aprendizagem de literatura e de letramento literário crítico.
\end{abstract}

Palavras-chave: Literatura; Linguística Sistêmico-Funcional; Ensino; Afeto.

\begin{abstract}
The aim of this article is to discuss literature teaching, which often deals superficially with the materiality of text. In addition, the article explores the emotion that reading provides, from a sociossemiotic perspective of language. Thus, understanding that literature is language, I attempt to develop the idea that literary texts are also accessible for linguistic analysis, since the text is language in use (HALLIDAY, 2002 [1964], 1994). The meanings constructed by the author in his/her literary discourse are closely linked to the context of the production and circulation of the book, that is, the text happens in its social environment. In relation to emotion, the center of attitudes and the heart of institutionalised feelings (MARTIN and WHITE, 2005), we need to understand that the pleasure of reading must figure as a protagonist in the process of teaching-learning literature and in critical literary literacy.
\end{abstract}

Keywords: Literature; Systemic-Functional Linguistics; Teaching; Emotion. 


\section{INTRODUÇÃO}

Escrever no prazer me assegura - a mim, escritor -o prazer de meu leitor? De modo algum. Esse leitor, é mister que eu o procure (que eu o "drague”), sem saber onde ele está. Um espaço de fruição fica então criado. Não é a "pessoa" do outro que me é necessária, é o espaço: a possibilidade de uma dialética do desejo, de uma imprevisão do desfrute: que os dados não estejam lançados, que haja um jogo.

Roland Barthes

O prazer do texto

O que acontece quando lemos uma obra literária? Podemos nos identificar (ou não) com os personagens ou até mesmo ter epifanias e catarses. De qualquer forma, o nosso relacionamento com um texto nunca é neutro, mas, ao contrário, é perpassado por inúmeros afetos, positivos ou negativos, que constroem significados em interação com o escritor. Segundo Barthes (1996, p, 21), no texto da epígrafe, um texto escrito com prazer não significa que será recebido do mesmo modo pelo seu leitor. O texto é repleto de lacunas que serão preenchidas por aquele que irá lê-lo (BARTHES, 1996). É necessário, portanto, que exista um "espaço de fruição", ou o que poderia chamar de um espaço de co-criação de significados entre escritor e leitor, que é o próprio jogo da leitura.

Para Jouve (2012, p. 82), o prazer não está vinculado ao que entendemos a partir de uma leitura. Além disso, o que compreendemos não obrigatoriamente corresponde àquilo que o autor tinha intenção de significar. $O$ texto só pode existir nessa dinâmica de troca, que afeta o leitor de algum modo. Uma obra literária não é um todo acabado, com sentidos prontos, mas um diálogo entre escritor e leitor que acontece no momento em que abrimos um livro e iniciamos sua leitura. Ler não é uma experiência solitária, mas sim solidária (DALVI, 2012; COSSON 2014). De acordo com Dalvi (2012, p. 21), o ato de ler não pode ser considerado uma mera decodificação:

Os sentidos são construídos, e não dados, no processo de interação (processo
este que é histórico, social e culturalmente situado). Quando construímos
uma leitura, estamos deixando vir à tona quem somos, o que pensamos, o que
sabemos, o que ignoramos (...). Nossas leituras (de textos e de mundo) estão
continuamente sujeitas à revisão (DALVI, 2012, p. 21)

Esses sentidos construídos pelo texto literário em interação devem ser priorizados no ensino de literatura. Contudo, a presença da literatura no espaço escolar quase sempre foi marcada pela necessidade de transmitir regras e princípios, que 
deveriam nortear a vida dos cidadãos, e de suprir o domínio do código verbal, cujo acesso se dava a partir dos padrões canonizados por escritores de determinada época. Este modelo de ensino de literatura, que, geralmente, deixa de lado o prazer de ler e a construção dos sentidos entre texto e leitor, está pautado em fornecer conhecimentos sobre literatura, incluindo elementos históricos e biográficos. O trabalho com o texto, quando acontece, muitas vezes é subordinado a objetivos alheios à fruição ou à dimensão humana da obra literária (SANTOS e JORGE, 2014, p. 186).

Dessa forma, considerando que a leitura é construção, a literatura precisa ser entendida como uma linguagem que constrói sentidos em seu contexto social, pois compartilhamos visões de mundo entre os homens no tempo e no espaço em uma mesma sociedade, ou seja, de forma situada (COSSON, 2014, p. 27). Os significados construídos pelo autor em seu discurso literário ${ }^{1}$ estão intimamente ligados ao contexto de produção e circulação da obra, ou seja, o texto só acontece em seu ambiente social. Segundo Cosson (2014, p. 47), ainda, a literatura é uma prática e um discurso, cujo funcionamento deve ser compreendido criticamente pelo aluno. No âmbito pedagógico, cabe ao professor despertar e fortalecer essa dimensão crítica e reflexiva, levando seus alunos a ultrapassar o simples consumo de textos literários.

Em meu entendimento, olhar para as tessituras e construções de significado do texto podem auxiliar professores e alunos, no contexto educacional, a irem além da própria leitura e ler nas entrelinhas. Sendo assim, penso que uma observação mais aprofundada do texto literário pode encontrar apoio nas análises fornecidas por teorias linguísticas. No âmbito dos estudos da linguagem, Harman (2008, p. 48) mostra que o uso da linguística na análise da literatura pode ser rastreado desde Aristóteles até teorias de cunho social como a Linguística Sistêmico-Funcional, doravante LSF.

A LSF é uma teoria de linguagem, cunhada a partir de estudos conduzidos por Halliday (1994), que entende que os significados são uma construção social. O autor percebe, ainda, que é parte da tarefa do linguista descrever textos, quaisquer que sejam, inclusive os textos literários (HALLIDAY, 2002 [1964]). O sistema linguístico oferece um elenco variado de significados e esse potencial da língua é o meio no qual um escritor realiza suas escolhas linguísticas, sejam elas conscientes ou não (HALLIDAY e MATTHIESSEN, 2004). Desse modo, por meio de sua base paradigmática, centrada

\footnotetext{
${ }^{1}$ Compreendo discurso literário aqui não como a designação do fenômeno literário, mas como a produção de significados que abrange questões ideológicas, contextuais e a própria materialidade do texto literário do autor, ou seja, o discurso literário é uma prática social que constrói representações e relações em uma mensagem textualmente organizada.
} 
das possibilidades que a língua oferece, a LSF enfatiza a importância do contexto no uso da linguagem, pois ele possui influência direta sobre as estruturas linguísticas observadas em qualquer discurso.

Sendo assim, este trabalho pretende discutir o ensino de literatura, que muitas vezes trata a materialidade do texto de forma superficial, e o afeto que a leitura proporciona a partir da perspectiva sociossemiótica de linguagem da LSF. Preciso reforçar, ainda, que acredito na interrelação entre os campos dos estudos literários e dos estudos linguísticos, visto que parece existir um vácuo no diálogo entre departamentos de língua e de literatura em muitas instituições. Encaixotamos o conhecimento, nos trancamos em salas separadas e, trabalhamos a portas fechadas, desconhecendo pesquisas e interesses de áreas afins que poderiam estar em colaboração mútua. Este artigo se encontra em um contexto de pesquisa que pretende estar em um entre-lugar desses campos do saber, se inserindo portanto no âmbito da Linguística Aplicada ${ }^{2}$.

\section{(DES)ENSINO DE LITERATURA?}

O ensino de literatura configura-se como uma questão relevante, pois, em minha opinião, a disciplina que é responsável por esse ensino trata a materialidade do texto de forma superficial, sem olhar todas as suas nuances. Muitas vezes, as aulas se resumem ao ensino dos estilos de época de forma cronológica e engessada, das características de autores e da historiografia literária. Em geral, uma possível análise crítica do texto é posta de lado e os alunos leem as obras em casa como livros paradidáticos. No papel de educador, é preciso questionar: como estamos ensinando literatura, se estamos ensinando? E, ao pensar na recepção, como será que nossos alunos aprendem literatura atualmente?

Segundo Cosson (2014), no ensino fundamental, os textos literários estão cada vez mais restritos a atividades de leitura ou, ainda, atividades de interpretação provenientes do livro didático, que trazem o texto incompleto, atividades com fichas de leituras, resumos de texto e debates, que visam somente recontar a história com as próprias palavras dos alunos. De acordo com Zilberman (2013, p. 226), a utilização do livro didático exclui a interpretação do aluno, exilando o leitor, imobilizando-o em

\footnotetext{
${ }^{2}$ A Linguística Aplicada é uma área de conhecimento autônoma, interdisciplinar, com forte preocupação social e que dialoga com teorias que atravessam o campo das ciências sociais e das ciências humanas. Para maiores esclarecimentos, ver Moita Lopes (2006; 2013).
} 
respostas fechadas, promovidas pelas fichas de leituras ou equivalentes que anulam a experiência de leitura.

No ensino médio, geralmente, o ensino limita-se à história da literatura brasileira, quase como apenas uma cronologia literária com estilos de época, cânone e dados biográficos dos autores. Nessas aulas informativas, os textos, em geral, são fragmentados e servem para comprovar as características dos períodos literários estudados. Do mesmo modo que Cosson (2014), penso que todas essas atividades de identificação e classificação de dados cerceiam o prazer de ler e servem como simples confirmação da leitura feita (COSSON, 2014, p 21-22).

O problema se amplia ainda mais no ensino superior, quando se nota, nos manuais introdutórios à teoria da literatura dos cursos de Letras, a ênfase na história das diferentes teorias ao longo dos anos. É certo que esse ensino é necessário, contudo, quando se torna dominante e central, acaba afastando o aluno de graduação, que é um futuro professor, da prática da teoria de sua própria disciplina. $\mathrm{O}$ aluno passa da história da literatura, no ensino médio, a uma história da teoria, no ensino superior, sem se deter no exercício da própria teoria (KRAUSE, 2013, p. 107-108). Sendo assim, nos ensinos fundamental e médio, a ênfase no ensino de literatura deve se dar na leitura, buscando qualidade e diversidade de gêneros, autores e nacionalidades.

Todorov (2009) diz que a literatura se encontra em perigo, pois o estudante não entra em contato com a leitura das obras literárias propriamente ditas, mas com a leitura de críticas (ou seja com a leitura de uma leitura), com a teoria e com a história da literatura, como já explicitei anteriormente. Sua reinvindicação é de que o texto literário volte a ocupar o centro do processo educacional e participe da formação cultural do cidadão. De acordo com o autor:

\footnotetext{
O conhecimento da literatura não é um fim em si, mas uma das vias régias que conduzem à realização pessoal de cada um. $\mathrm{O}$ caminho tomado atualmente pelo ensino literário, que dá as costas a esse horizonte ("nessa semana estudamos metonímia, semana que vem passaremos à personificação"), arrisca-se a nos conduzir a um impasse - sem falar que dificilmente poderá ter como consequência o amor pela literatura (TODOROV, 2009, p. 33).
}

Segundo Meira, na apresentação da edição brasileira da obra de Todorov (2009), se transportarmos a proposta do autor para o caso brasileiro, temos a ideia de que Machado de Assis, por exemplo, não seja apresentado em primeiro lugar como escritor de transição entre o Romantismo e o Realismo, ou mesmo como iniciador do Realismo 
no Brasil, mas que suas obras sejam lidas e discutidas antes de serem classificadas ou periodizadas (2009, p. 11). Portanto, são as obras e seu contexto de produção que devem ser estudadas e não as ferramentas de análise ou escolas literárias de forma descontextualizada. Essa concepção vai de encontro ao aporte teórico fornecido pela LSF, que percebe a importância do contexto para compreensão da obra.

$\mathrm{Na}$ LSF, o contexto se dá em dois níveis extralinguísticos: o contexto de cultura e o contexto de situação. O contexto de cultura pode ser considerado o ambiente sociocultural mais amplo, no qual se inclui a ideologia, as convenções sociais e as instituições. Inserido no contexto de cultura, temos o contexto de situação, que consiste nas variações de linguagem mais particulares dentro de cada cultura, e que se manifestam por meio de três variáveis: (i) campo, que diz respeito à natureza da prática social, à atividade que está acontecendo; (ii) relações, que diz respeito à natureza da ligação entre os participantes da interação; e (iii) modo, que refere-se à como a comunicação ocorre e determina os significados textuais.

Desse modo, quando Eagleton (1983 apud HARMAN, 2008, p. 53) percebe a literatura como uma construção ideológica utilizada para satisfazer gostos e necessidades dominantes e contextos sociopolíticos de uma época, me parece oportuno e adequado lançar mão da LSF como teoria de linguagem e ferramenta metodológica na análise dos textos literários, principalmente no ensino de literatura. Como disse inicialmente, o contexto é o ativador das escolhas semânticas que um escritor faz, i.e., é o ambiente em que o texto ganha significado. É por essa razão que cada escolha linguística adquire relevância quando comparada às outras opções potenciais que poderiam ter ocorrido, mas que foram preteridas (SALGADO, 2014, p. 28).

Quando pensamos sobre o processo de ensino-aprendizagem de literatura, de fato, as questões são muitas: por que (de)limitar o estudo da literatura a uma determinada linha do tempo e não trabalhar com autores variados, com temas de interesse da turma e com gêneros requeridos pelo contexto social dos alunos? Por que apenas o professor possui o poder de escolha das obras literárias que serão trabalhadas ao longo do ano (e que muitas vezes são lidas em casa pelos alunos, recorrendo a resumos e não lendo, de fato, o texto proposto)? Por que temos a necessidade de encaixotar conhecimentos adquiridos e depositá-los mais e mais em diferentes “departamentos do saber", como se saber mais fosse sinal de verdadeiro aprendizado?

O que é aprendido precisa ter uma função na vida do aluno, precisa fazer sentido a partir de suas práticas sociais. Ou seja, a leitura literária precisa ser uma prática 
significativa, que perceba como a literatura pode nos ajudar a enxergar o mundo e a nós mesmos. Nesse sentido, Cosson (2014) parafraseia a distinção feita por Halliday (1994) para o aprendizado da linguagem ${ }^{3}$, e mostra que é necessário o aprendizado da literatura, que é a própria experiência do mundo por meio da palavra; o aprendizado sobre a literatura, os conhecimentos sobre história, teoria e crítica, que, em geral, são colocados como única parte do processo; e o aprendizado por meio da literatura, que mostra quais saberes e habilidades a prática da leitura pode proporcionar.

No mundo, os conhecimentos não são oferecidos dentro de "caixinhas". Desse modo, acredito que a didatização acaba, por vezes, engessando o conhecimento que poderia ser construído pelos alunos. Temos colocado nossos próprios sentimentos em caixas isoladas, contudo, na realidade, sabemos que o mundo é preenchido por paradoxos e assim também é a sala de aula. É impossível separar a cabeça do coração, a razão da emoção, os fatos dos sentimentos. Como resultado dessa divisão, temos teorias que pouco tem a ver com a prática, como é possível observar no ensino de literatura. Separamos o ensino da aprendizagem, por isso temos professores que falam, mas não ouvem e estudantes que escutam, mas não falam (PALMER, 2007, p. 66). Penso que um letramento literário só poderá ser efetivo quando professores e alunos aceitarem seus próprios paradoxos, para que possam olhar os paradoxos da própria ficção.

Segundo Allwright (2000, p. 1), nossa sociedade acredita em uma noção de progresso intelectual individual, ou seja, quanto mais ficamos velhos, mais esperamos saber e fazer melhor uso dos conhecimentos que armazenamos. Pensamos que estamos progredindo, avançando, entretanto nossas perguntas sobre o processo de ensinoaprendizagem continuam sendo as mesmas de trinta anos atrás (por exemplo, qual o melhor método?). Allwright está, aqui, pensando na aprendizagem de línguas, no âmbito da Prática Exploratória ${ }^{4}$, porém acredito que suas ideias possam ser aplicadas ao ensino-aprendizagem de literatura.

\footnotetext{
${ }^{3}$ Halliday (2004) descreveu um modelo de linguagem desenvolvido em três níveis: o aprendizado de linguagem, que compreende os atributos básicos de uma língua como ouvir, falar, ler e escrever; aprendizado através da linguagem, que refere-se à construção de realidade e atividades sobre o mundo representado através de recursos de linguagem; e o aprendizado sobre a linguagem que é o entendimento da natureza e funcionamento da própria língua, ou seja, toma-la como objeto de estudo: aprendizagem sobre o sistema gramatical, por exemplo.

${ }^{4}$ A Prática Exploratória é uma abordagem de pesquisa que propõe desenvolver o entendimento da vida da sala de aula, sendo inserida naturalmente no cotidiano das práticas pedagógicas. Um dos objetivos desta abordagem é gerar qualidade de vida para os praticantes (professores e alunos). Para maiores esclarecimentos, ver Allwright e Hanks (2009).
} 
Quando pensamos no conhecimento de forma cumulativa, nos remetemos à uma concepção tecnicista da educação em que cada geração deve ser melhor que a geração passada. Allwright (2000) considera o progresso pedagógico alcançado como algo cumulativo, tanto de forma individual quanto coletiva, é concluir que fazemos algo "tolo", pois, à medida que nos aproximamos de um conhecimento "maior", percebemos o estado de "conhecimento primitivo" no qual estávamos antes (ALLWRIGHT, 2000). Quando consideramos o conhecimento como algo não cumulativo, poderemos fazer perguntas mais adequadas, que são válidas apenas por um determinado período de tempo, já que o mundo está em constante mudança e perguntas diferentes são necessárias para circunstâncias diferentes (ALLWRIGHT, 2000, p. 2).

Dessa forma, o que podemos entender como progresso no ensino de literatura? Como nas artes, de uma forma geral, acredito que não podemos compreender o conhecimento de forma cumulativa. Quando falamos do ensino da leitura literária, não faz sentido essa busca por uma "melhora" no sentido de acumulo de leituras ou saber escolástico sobre diversos autores. Saber mais sobre as escolas literárias e sobre a história da literatura sem conexão com o texto poderá fazer com que nossos alunos progridam em suas leituras? Decorar as inúmeras figuras de linguagem pode fazê-los compreender melhor seu próprio mundo?

Penso que, talvez, seja o foco no discurso literário, isto é, na materialidade do texto, em conexão com seu contexto, o que pode levar o aluno a ir além de decorar conteúdos para passar na prova. Essa concepção não se alinha com a ideia de ler mais é ler melhor como uma questão de quantidade, mas ler em um trabalho de (des)contrução do texto, em temos de qualidade da leitura. Em suma, é preciso estabelecer um contínuo entre quantidade e qualidade. Isso seria, em minha concepção, ressignificar a noção de progresso no ensino de literatura.

Segundo Zilberman (2013), para a questão do ensino se faz necessário uma proposta de que enfatize a leitura dos textos em sala de aula, recuperando o contato do aluno com a obra de ficção, estimulando uma vivência da obra, que é também uma descoberta do próprio mundo (ZILBERMAN, 2013, p. 226). Toda a interpretação realizada é válida, pois é a co-criação de um universo possível a partir da obra literária e impede o estabelecimento de uma verdade única como a correta. Nessa proposta, é preciso que exista um pacto entre professor e aluno, fazendo desaparecer as hierarquias rígidas que existem entre eles, e sobre a qual se apoia o sistema educativo 
(ZILBERMAN, 2013, p. 227). Essa é uma aliança mais democrática, em que o aluno é co-construtor de seu conhecimento e o professor deve estar aberto para o diálogo.

É preciso considerar o aluno como um sujeito autônomo e convidá-lo a uma apropriação singular das obras de modo que aconteça um deslocamento do "ensino de literatura" para uma concepção de ensino da "leitura literária", uma vez que o primeiro se concentra no professor e o segundo no aluno. Esse deslizamento de ênfase não se dá apenas na literatura, mas sim no âmago das tendências pedagógicas de forma geral (REZENDE, 2013, p. 105-106). Allwright corrobora essa visão, ao propor que os alunos também são pesquisadores de sua própria prática. Alunos, assim como os professores, são indivíduos únicos, capazes de aprender e de desenvolver seu próprio aprendizado. Os alunos são a chave de seu próprio desenvolvimento, são protagonistas no processo de ensino-aprendizagem (ALLWRIGHT e HANKS, 2009).

De acordo com Freire (1979, p. 27), qualquer reflexão sobre a educar é uma reflexão sobre o próprio ser humano, que deve ser sujeito de sua própria educação, i.e., o aluno deve ser construtor do seu conhecimento, pois o sujeito da aprendizagem é um ser autônomo. Contudo, essa "busca" pelo conhecimento também significa dependência, pois o ser humano não é uma ilha. Precisamos de nossa relação com o outro e com o mundo. O homem é um ser do mundo, que está no mundo e com o mundo (FREIRE, 1979, p. 30). Corroborando essa visão, Demo (2001) mostra que saber pensar e saber aprender é fazer-se sujeito da própria história individual e coletiva, ou seja, ser um sujeito autônomo. O fenômeno da aprendizagem é um processo criativo e crítico, em que realizamos interpretações próprias de dados e informações para transformá-los em conhecimento (DEMO, 2001, p. 48-49). Nesse contexto, a autonomia se dá em uma relação dialética com a dependência, pois nenhuma autonomia é ilimitada (DEMO, 2001, p. 51-52).

Considerando essa noção de autonomia situada no mundo e em nossas práticas sociais, como podemos pensar em nossos alunos como construtores de seu próprio saber literário? Creio que o afeto é a força motriz na promoção desse saber literário. Como vimos nessa seção, o ensino, atualmente, se encerra em muitas práticas que deixam o prazer de aprender e o prazer de ler fora da sala de aula. Para construir esse saber literário situado, é preciso, antes de mais nada, recuperar o que nos afeta diante da leitura. 


\section{O PARADOXO DO AFETO}

Quando escolarizamos a literatura, também é necessário nos relacionarmos com ela de forma afetuosa. Segundo Freire (1979, p. 29), não há educação sem amor, ou seja, não há educação imposta ou que seja feita pelo medo. Quando há amor, afeto, não se teme a educação. Sendo assim, creio que a escola não pode deixar de lado o prazer da leitura; ao contrário esse prazer precisa protagonizar qualquer método de ensinoaprendizagem.

Conforme Jouve (2012, p. 45), se a leitura não gerar imediatamente prazer, frequentemente rejeitaremos o livro antes mesmo de ter uma visão mais precisa do que ele tem a dizer. Essa leitura escolarizada e que pode ser realizada com prazer é a que formará leitores na escola. No início deste artigo, comento que nossa relação com a literatura sempre nos afeta de alguma forma. Ler, em geral, é um ato de prazer. Muitos dos que chegaram a uma Faculdade de Letras, o fizeram por amor às letras - àquelas que estão inscritas em tantos livros lidos e não às Letras abstratas da academia. Contudo, há um paradoxo que desejo de explorar: (i) o mito de que os jovens não leem e (ii) o fato de que, em algum momento de nossa vida escolar, ler pode ser tonar muito penoso para algumas pessoas.

Uma das reclamações mais repetidas dos professores em geral, de literatura em particular, é a de que os seus alunos não leem nada. Porém, muitos alunos, na verdade, não leem a maioria dos textos que seus professores exigem que eles leiam, o que não significa que eles não leem nada - uma generalização apressada e errônea. Um professor só pode afirmar que os seus alunos não leram os textos que ele mesmo mandou que eles lessem (KRAUSE, 2015, p. 1).

Krause (2015), assim como Cosson (2014), enfatiza que cabe a nós, professores, desde a classe de alfabetização até o doutorado, ensinar a ler. Entretanto, para realizar essa tarefa precisamos dar o exemplo, isto é, ler junto com os alunos, em sala, e oferecer leituras que levem o aluno a níveis cada vez mais complexos de compreensão (KRAUSE, 2015, p. 1). Dizer que os alunos não leem nada é falacioso e equivale a afirmação que nós ensinamos, eles é que não aprendem (KRAUSE, 2015, p. 1). Em minha opinião, os alunos querem ler com autonomia. Por que não ousar integrar o que o aluno "quer ler" com o que ele "precisa ler"? Será que apenas o professor detém conhecimento, saber e poder para escolher o que o aluno deve ler ou mesmo precisa ler? Por que o aluno não pode fazer suas próprias escolhas? 
Na escola, os critérios de seleção das obras estão ligados aos programas e currículos, à questão da legibilidade das obras, que dividem os leitores por faixa etária, às condições para oferecimento da leitura literária e, ainda, à gama de leituras do próprio professor, que é o grande intermediário entre o livro e o aluno. Isso explica a permanência de algumas obras por décadas nas escolas (COSSON, 2014, p. 32). Muitas vezes, o que o professor leu quando estava no ensino fundamental e médio é o que ele indica aos alunos. Diante desses fatores, é possível questionar: como selecionar os livros para o letramento literário?

De acordo com o autor (COSSON, 2014, p. 32), até bem pouco tempo, bastava ao professor seguir o cânone, que é tido como o conjunto de obras representativas de uma nação ou de um idioma. Contudo, atualmente, o cânone vem sendo questionado e uma outra direção para seleção de obras seria a contemporaneidade do texto. Essa perspectiva leva em consideração a aparente facilidade de leituras das obras, que tratam de temas e utilizam uma linguagem que pertence ao horizonte de seus leitores (COSSON, 2014, p. 33).

O letramento literário precisa trabalhar sempre com o atual, seja ele contemporâneo ou não (COSSON, 2014, p. 34). Ser atual é ter um sentido além do próprio texto, que pode ser co-construído a partir de nossas práticas sociais. Dessa forma, as obras precisam ser diversificadas, para que o aluno tenha várias perspectivas sobre o mundo e possa construir os seus próprios modos de vê-lo. Devo avançar ao dizer que o aluno, como sujeito autônomo e construtor de seu próprio conhecimento (FREIRE, 1979; DEMO, 2001), precisa participar de forma ativa da escolha do que ele mesmo irá ler, afinal nem todos precisam ler os mesmos livros. Professor e aluno devem construir seu próprio cânone, aquilo que representa a prática social de uma comunidade, de uma turma e de cada aluno de forma individualizada.

O fato de considerar as leituras do aluno como válidas e sua autonomia mostra que o lugar do professor é sem dúvida um lugar de poder, mas um poder cada vez menor, o que é positivo (KRAUSE, 2015). Nós, educadores, precisamos aprender a aprender cada vez mais e a perceber que somos tão aprendizes quanto nossos alunos. Segundo Demo (2001), não existe diferença social entre professor e aluno. Os dois estão em um eterno processo de aprendizado. O aluno só tem espaço para desenvolver afeto pela leitura, se o seu professor demonstra esse mesmo afeto pelos livros que ele mesmo lê. Freire $(1979$, p. 32) nos disse que a educação deve ser desinibidora e não restritiva. É 
preciso dar a oportunidade que o aluno seja ele mesmo, desenvolvendo assim sua consciência crítica.

Em meu entendimento, o professor precisa deixar de ser como um ser superior que ensina aos alunos ignorantes ou tábulas rasas. É preciso deixar de ver o aluno apenas como um recipiente passivo de conhecimentos, como se eles fossem meros depositórios do saber que nós, professores, detemos. Essa é a concepção da educação bancária descrita por Freire $(1979$, p. 38), que pensa que quanto mais se sabe, mais se sabe. Uma noção conteudística, mecanicista, corroborada pela concepção que nossa sociedade entende como progresso (ALLWRIGHT, 2000).

Em lugar de "transmitir conteúdos", o ensino de literatura deve se preocupar em conquistar o aluno para o livro. O professor o faz, quando provoca, desafia seu aluno e, principalmente, quando não se demite do seu lugar de professor (KRAUSE, 2013, p. 84). O educador além de ler as mesmas obras que seus alunos e se entusiasmar com elas, também precisa reconhecer que não existe uma única interpretação, afinal a literatura é plural e criadora de múltiplos significados e perspectivas. Cabe ao professor, estimular o aluno à reflexão e ao refinamento de sua própria perspectiva (KRAUSE, 2013, p.85).

Por vezes a literatura acaba se tornando um mistério, algo inacessível cuja iniciação está fora de alcance (COSSON, 2014, p. 11). Isso se dá, talvez, pela forma como ela é retratada, em um ensino que não se preocupa com a materialidade do texto, tampouco em fazer com que o aprendiz produza conexões que façam sentido em sua vida. O conhecimento precisa fazer sentido na vida social, em nosso mundo, para ser internalizado. Precisamos fazer associações com a prática e ir do concreto ao abstrato em uma relação dialética. Isso leva, de fato, a apropriação de conceitos, pois só aprendemos quando fazemos elos entre conhecimento e nossa prática social.

Se somos obrigados pela escola a ler somente aquilo que não queremos, sem que essas obras façam qualquer conexão com nossa vida, como podemos nos sentir afetados por elas? Como produzir o espaço de fruição, que é o próprio prazer da leitura, fundamental para nossa formação como leitores? $\mathrm{Ou}$, ainda, como formar leitores profícuos, quando somos obrigados a ler em casa, sozinhos, sem que a sala de aula se torne um espaço de reflexão crítica da obra, mas apenas um lugar para aprender conceitos e matérias descontextualizadas?

O processo afetivo está na base do princípio de identificação, que é o motor essencial da leitura, e é uma dimensão escolarizável. Por outro lado, é impossível que a 
leitura afete nossos alunos apenas com fragmentos de livros didáticos, por exemplo, de forma descontextualizada (REZENDE, 2013, p. 110). Dessa forma, a escola precisa mudar, considerando a leitura como uma dimensão social e individual. Talvez o maior problema do ensino da leitura literária não resida na resistência dos alunos à leitura, mas na falta de um espaço-tempo para esse conteúdo de reflexão, de prazer e de elaboração. Essa é uma perspectiva de formação não prevista nos currículos e não cabível no ritmo da cultura escolar que massifica os alunos (REZENDE, 2013, p. 111). Dessa forma, uma necessidade palpável da escola atual é trabalhar com as idiossincrasias, com as individualidades, inclusive no ensino da leitura literária.

Mesmo aprendendo a ler e conservando essa habilidade, a criança não se converte necessariamente em um leitor, já que este se define, em princípio, pela assiduidade à literatura. A escola pode ficar no meio do caminho: ou cumpre sua tarefa de transformar a o indivíduo habilitado à leitura em um leitor, saindo da alfabetização e caminhando para um letramento literário; ou arrisca-se no caminho inverso, levando o aluno ao afastamento de qualquer leitura (ZILBERMAN, 2013, p. 221).

Cosson (2014) nos mostra que uma das pressuposições do senso comum sobre leitura e literatura é que os livros falam por si mesmos e a atividade de leitura bastaria, portanto, como atividade escolar para o processo de letramento literário. Contudo há um estranhamento: se lemos com prazer fora da escola, sem instruções específicas, por que ela deveria se preocupar tanto com a leitura? Os livros não falam por si mesmos, mas por meio dos mecanismos de interpretação que utilizamos (COSSON, 2014, p. 26). O objetivo da leitura, então, deve ser mais do que entretenimento, mas proporcionar ao aluno entrar, de fato, no "espaço de fruição", abrindo uma porta entre ele e o escritor, afinal o modo como lemos fora da escola é, muitas vezes, formado dentro dela.

Entretanto, como fazer com que nossos alunos sintam prazer pela leitura? Ou mesmo que se sintam afetados por ela de alguma forma? Como podemos situar essa concepção de afeto no ensino de literatura? Mahn e Steiner (2002) discutem a existência de uma ampla variação no modo como a emoção é representada nas ciências humanas. Pesquisas recentes sugerem que o afeto está ligado a áreas específicas no cérebro e sua expressão é determinada pela situação social. O afeto está relacionado com a interação, com nossas trocas comunicativas. Se, por um lado, as interações em sala podem ser de colaboração intensa, pelo outro, podem afastar professores e alunos.

$\mathrm{O}$ afeto é fundamental na transformação da prática educacional e desempenha um papel crucial para a aprendizagem e a criatividade, principalmente quando essas 
atividades e as interações são reforçadas, conforme Mahn e Steiner (2002), pelo "dom da confiança". Essa concepção remete à Freire (1979) e a educação pelo amor, que não admite o medo. Nossas aulas de literatura precisam, em meu entendimento, se voltar para esse aspecto emocional inerente à própria linguagem e, além disso, conectar o ser humano às suas interações e práticas sociais. Segundo Cosson (2014), a leitura literária humaniza e é por meio desse afeto que podemos ressignificar os textos.

No âmbito a LSF, o sistema de avaliatividade (MARTIN e WHITE, 2005) pode fornecer embasamento teórico para pensar sobre a relação entre linguagem e emoção. Todos os momentos expressamos pensamentos, opiniões, sentimentos e atitudes em relação a alguém, a algo que acontece ou a algum objeto, ou seja, o tempo todo, estamos avaliando e sendo avaliados. É possível conceituar o sistema de avaliatividade, então, como um conjunto de significados interpessoais ${ }^{5}$ que se inclinam sobre os mecanismos de avaliação, da apreciação e do julgamento difundidos pela linguagem.

Tais mecanismos, assim, formam um sistema que fornece aos usuários da língua alternativas de empregar recursos avaliativos nas interações cotidianas (VIAN Jr., 2010, p. 11). De acordo com Martin e White (2005, p. 07), os recursos interpessoais estão preocupados com a negociação de relações sociais, ou seja, como as pessoas estão interagindo, incluindo os sentimentos que tentam compartilhar.

O sistema de avaliatividade é composto por três subsistemas: (i) atitude, (ii) gradação; e (iii) engajamento. O subsistema da atitude, mais especificamente, abrange três campos semânticos, que são as atitudes de afeto (quando são utilizados recursos para expressar emoção), julgamento (quando são utilizados recursos para julgar o caráter) e apreciação (quando são utilizados recursos para atribuir valor às coisas). Segundo Martin e White (2005, p. 45), quando expressarmos nossas atitudes, por meio do julgamento e da apreciação, podemos vislumbrá-las como sentimentos institucionalizados. O julgamento refere-se ao universo das propostas sobre o comportamento, sobre como devemos nos comportar ou não, e a apreciação ao universo das proposições sobre o valor das coisas, se elas valem a pena ou não.

\footnotetext{
${ }^{5} \mathrm{Na}$ LSF, o sistema linguístico é negociado na interação e realizado, léxico-gramaticalmente, por meio das Metafunções que ocorrem de forma simultânea na língua: o significado ideacional (representação da experiência sobre o mundo) se realiza por meio da Metafunção Ideacional e do seu sistema de Transitividade; o significado interpessoal (estabelecimento e manutenção das relações sociais), na Metafunção Interpessoal e no seu sistema de Modo; e o significado textual (organização das mensagens), por meio da Metafunção Textual e do seu Sistema de Tema e Rema. Para maiores esclarecimentos teóricos, ver Halliday (1994) e Halliday e Matthiessen (2004).
} 
O afeto é o centro das atitudes que expressamos (VIAN Jr., 2010, p. 20). Esse recurso semântico é utilizado para realizar as emoções linguisticamente no discurso. Ele diz respeito à emoção, isto é, a uma avaliação pautada nos sentimentos dos falantes/escritores indicando como se comportam emocionalmente em relação às pessoas, às coisas, aos objetos e aos acontecimentos (MARTIN, 2000, p.148). Quando lemos uma obra literária e nos sentimos afetados por ela, certamente expressaremos nossa emoção por meio do afeto, do julgamento das personagens e da apreciação da própria obra. Dessa forma, a escuta do professor se torna um aliado no processo de ensino-aprendizado. Precisamos escutar o que nossos próprios alunos têm a narrar sobre a leitura literária, afinal todos somos autores de pequenas histórias.

Além disso, leitores podem se tornar coautores do texto, se identificando com a emoção expressa por um personagem de forma autoral. Sendo assim, ao analisar o discurso literário ou as emoções que envolvem a leitura de uma obra, acredito que observar que tipos de, qual a intencionalidade dessas escolhas linguísticas (sejam elas conscientes ou não) e como elas interagem na construção de sentidos do texto é uma ferramenta para formar uma leitura crítica e reflexiva das obras. Logo, é necessário refletir sobre os posicionamentos que estão sendo levados às salas de aula. Como disse no início deste ensaio, nosso relacionamento com um texto nunca é neutro, mas é perpassado por afetos que constroem significados em interação com o escritor.

Finalmente, é preciso reconhecer a complexidade de uma sala de aula e do processo de ensino-aprendizagem. Nós aprendemos fazendo conexões com nossas práticas sociais e nossa sala de aula também é uma prática social. Nesse sentido, alunos e professores são aprendizes, pois há uma co-construção de conhecimentos. Compreender que a aprendizagem é um processo constante, contínuo, que deve ser construído junto com o aluno é o primeiro passo, em minha percepção, para que possamos caminhar juntos em colaboração. É preciso compreender, ainda, que estamos sempre nesse processo de aprendizagem, sejamos alunos ou professores, afinal a educação não é um produto pronto, acabado.

\section{REFERÊNCIAS}

ALLWRIGHT, D. The notion of progress. In. Research on language teaching and learning. Lancaster. Unpubished manuscript. Lancaster University, 2000.

ALLWRIGHT, D.; HANKS, J. The Developing Learner: An Introduction to Exploratory Practice. Palgrave Macmillan, Basingstoke, UK, 2009. 
BARTHES, R. O prazer do texto. Trad. I. Guinsburg. São Paulo: Perspectiva, 1996.

COSSON, R. Letramento literário: teoria e prática. (2ªed.) São Paulo: Contexto, 2014.

DALVI, M. A. Ensino de Literatura: algumas contribuições. In: UYENO, E. Y.; PUZZO, M. B.; RENDA, V. L.B. da S. (Org.). Linguística Aplicada, Linguística e Literatura: intersecções profícuas. 1ed.Campinas: Pontes, 2012, v. 1, p. 15-43.

DEMO, P. Saber Pensar. São Paulo: Cortez, 2001.

EAGLETON, T. Literary theory. Cambridge, MA: Blackwell, 1983.

FREIRE, P. A educação e o processo de mudança social. In. Educação e Mudança. São Paulo: Paz e Terra, 1979.

HALLIDAY, M. A. K. An Introduction to Functional Grammar. (2 ed.). London: Edward Arnold, 1994.

HALLIDAY, M. A. K. The linguistic study of literary text. In. In WEBSTER, J.J. (ed.), Linguistic Studies of Text and Discourse. London and New York: Continuum, 2002 [1964].

HALLIDAY, M.A.K. Three Aspects of Children's Language Development: Learning Language, Learning through Language, Learning about Language. In WEBSTER, J.J. (ed.), The Language of Early Childhood. New York: Continuum, 2004.

HALLIDAY, M.A.K.; MATTHIESSEN, C. An introduction to functional grammar. ( $3^{\mathrm{a}}$ ed.). Londres: Hodder Arnold, 2004.

HARMAN, R. Systemic Functional Linguistics and the teaching of literature in urban school classrooms. University of Massachusetts Amherst, 2008.

JOUVE, V. Por que estudar literatura? Trad. Marcos Bagno e Marcos Marcio-lino. São Paulo: Parábola, 2012.

KRAUSE, G. B. Conversas com um professor de literatura. Rio de Janeiro: Rocco, 2013.

KRAUSE, G. B. Por que os professores acham que os alunos não leem nada? Revista Eletrônica do Vestibular, v. 8, 2015.

MAHN.H; STEINER. V. The gift of the confidence: a vygotskian view of emotions. In: WELLS, G.; CLAXTON, G (Eds.). Learning for life in the $21^{\text {st }}$ century. P. 46-58, Oxford: Blackwell Publishers, 2002.

MARTIN, J. R.; WHITE, P. The language of evaluation: appraisal in English. New York: Palgrave, 2005. 
PALMER, P. J. The Hidden Wholeness. In. The Courage to teach: exploring the inner landscape of teacher's life. San Francisco: Jossey-Bass Publishing, 2007.

REZENDE, N. L. de. O ensino de literatura e a leitura literária. In: DALVI, M. A.; REZENDE, N. L. de.; JOVER FALEIROS, R. (Org.). Leitura de literatura na escola. São Paulo: Parábola, 2013. P. 99-112.

SAlGADO, O. F. A. As representações de Deus em "Caim", de José Saramago: um estudo sistêmico-funcional. 2014. Dissertação (Mestrado em Letras) - UERJ.

SANTOS, C. D. dos; JORGE, S. R. Literatura e ensino: um tema e seus problemas. Gragoatá, Niterói, n. 37, p. 177-200, 2. sem. 2014.

TODOROV, T. A literatura em perigo. Trad. Caio Meira. $3^{\text {a }}$. Ed. Rio de Janeiro: DIFEL, 2010.

VIAN JR. O. O sistema de avaliatividade e a linguagem da avaliação. In: VIAN JR., O; SOUZA, A. A. de; ALMEIDA, F. S. D. P. (Orgs.). A linguagem de avaliação em língua portuguesa. Estudos sistêmico-funcionais com base no sistema de avaliatividade. São Carlos: Pedro e João Editores, 2010.

ZILBERMAN, R. Porque a leitura da literatura na escola. In: GERHARDT, A. F. L. M.; AMORIM, M. A. de; CARVALHO, A. M. (Org.). Linguística aplicada e ensino: língua e literatura. 1ed.Campinas: Pontes, 2013, v. 1, p. 209-230.

\section{A AUTORA}

Odete Firmino Alhadas Salgado é Mestre em Linguística pela Universidade do Estado do Rio de Janeiro (2014) e graduada em Letras pela mesma instituição (2011). Atualmente, cursa Doutorado em Estudos da Linguagem na Pontifícia Universidade Católica do Rio de Janeiro com bolsa de fomento do Conselho Nacional de Desenvolvimento Científico e Tecnológico (CNPq). Sua pesquisa se insere no âmbito da Linguística Aplicada com o embasamento teórico da Linguística SistêmicoFuncional, trabalhando em interface com os estudos literários.

E-mail: odete.letras@gmail.com 